\title{
Age- and sex-specific pediatric LMS-Percentiles for Laboratory Parameters enabled by Data mining
}

\section{Thomas Hundhausen ( $\nabla$ thomas.hundhausen@uia.no)}

1. Department of Medical Biochemistry, Southern Norway Hospital Trust, Agder, Norway; 2. Department of Natural Sciences, University of Agder, Norway https://orcid.org/0000-0002-0466-7342

\section{Andre Madsen}

Department of Medical Biochemistry and Pharmacology, Haukeland University Hospital, Bergen, Norway https://orcid.org/0000-0003-1425-2148

\section{Data Note}

Keywords: LMS, percentiles, laboratory medicine, pediatrics, statistics, reference intervals

Posted Date: January 5th, 2022

DOI: https://doi.org/10.21203/rs.3.rs-1228207/v1

License: (9) This work is licensed under a Creative Commons Attribution 4.0 International License. Read Full License 


\section{Abstract}

\section{Background:}

Various laboratory parameters routinely measured in pediatric practice covariate with sex and age. Conventional reference intervals are not suitable to account for this variation. Here we demonstrate construction of continuous LMS percentile curves from routine laboratory data. This allows adequate adjustment for both sex- and age-dependent covariation in childhood.

\section{Material and Methods:}

Anonymized routine blood test results requested by primary health care physicians were collected, outliers excluded and LMS-models generated in R.

\section{Results:}

Percentiles for several biomarkers derived from a regional population were established in the 'LMS' framework and provided here for comparison with etablished reference ranges, discussion and, potentially, clinical use.

\section{Conclusion:}

The reference framework 'LMS' is well-known from pediatric growth charts and can also be used in laboratory medicine.

\section{Introduction}

Pediatric growth charts are reference sets of continuous LMS-percentile curves(1)for a range of essential age- and sex-related variables, e.g. anthropometric height, weight, head-circumference, and body-mass index. Growth curves represent important tools for pediatricians to longitudinally monitor child development in health and disease and visually track developmental status of patients(2). Various laboratory parameters routinely measured in pediatric practice also covariate with sex and age(3). However, pediatric percentiles curves for common laboratory parameters rarely exist. Here we demonstrate construction of continuous LMS percentile curves from routine laboratory data and deposit the underlying LMS-models.

\section{Material}

Data was acquired as anonymized routine test results for pertinent biochemical markers that vary with age and/or sex in childhood and adolescence, requested by primary health care physicians. Ethical approval was obtained from the Western Health Regional Ethics Committee, Norway (REK-vest/265205). 
Duplicate identities were removed and the chronologically first result per individual was retained. Likely outliers were excluded(4). Reference percentiles were modelled using the LMS algorithm provided in the 'gamlss' package in $R(5)$. Model conformity to normality within acceptable skewness (L), mean (M), coefficient of variation (S) and kurtosis $(\mathrm{K})$ was evaluated by Q-tests. Residual distribution was evaluated by z-score histograms, worm plots and detrend Q-Q plots(6).

\section{Results}

LMS reference curves applied to $\log ($ biomarker*1e6) data are visualized in attachment 1 


\begin{tabular}{|c|c|c|c|c|c|}
\hline Model name & Biomarker & Gender & $\begin{array}{l}\text { Sample } \\
\text { size }\end{array}$ & Method & SI unit \\
\hline SSHFCREATININEF & Creatinine & Female & 11570 & $\begin{array}{l}\text { Roche Cobas, } \\
\text { enzymatic }\end{array}$ & $\mu \mathrm{mol} / \mathrm{L}$ \\
\hline SSHFCREATININEM & Creatinine & Male & 9844 & $\begin{array}{l}\text { Roche Cobas, } \\
\text { enzymatic }\end{array}$ & $\mu \mathrm{mol} / \mathrm{L}$ \\
\hline SSHFTCF & Total cholesterol & Female & 6309 & Roche Cobas & $\mathrm{mmol} / \mathrm{L}$ \\
\hline SSHFTCM & Total cholesterol & Male & 5134 & Roche Cobas & $\mathrm{mmol} / \mathrm{L}$ \\
\hline SSHFTSHF & TSH & Female & 17502 & Roche Cobas & $\mathrm{mlU} / \mathrm{L}$ \\
\hline SSHFTSHM & TSH & Male & 12783 & Roche Cobas & $\mathrm{mlU} / \mathrm{L}$ \\
\hline SSHFFT3F & Free T3 & Female & & Roche Cobas & $\mathrm{pmol} / \mathrm{L}$ \\
\hline SSHFFT3M & Free T3 & Male & & Roche Cobas & $\mathrm{pmol} / \mathrm{L}$ \\
\hline SSHFFT4F & Free T4 & Female & 18213 & Roche Cobas & $\mathrm{pmol} / \mathrm{L}$ \\
\hline SSHFFT4M & Free T4 & Male & 7362 & Roche Cobas & $\mathrm{pmol} / \mathrm{L}$ \\
\hline SSHFUAF & Uric acid & Female & 7519 & Roche Cobas & $\mu \mathrm{mol} / \mathrm{L}$ \\
\hline SSHFUAM & Uric acid & Male & 5646 & Roche Cobas & $\mu \mathrm{mol} / \mathrm{L}$ \\
\hline SSHFLDLF & LDL cholesterol & Female & 10668 & Roche Cobas & $\mathrm{mmol} / \mathrm{L}$ \\
\hline SSHFLDLM & LDL cholesterol & Male & 8692 & Roche Cobas & $\mathrm{mmol} / \mathrm{L}$ \\
\hline SSHFHDLF & HDL cholesterol & Female & 9296 & Roche Cobas & $\mathrm{mmol} / \mathrm{L}$ \\
\hline SSHFHDLM & HDL cholesterol & Male & 7426 & Roche Cobas & $\mathrm{mmol} / \mathrm{L}$ \\
\hline SSHFALPF & $\begin{array}{l}\text { Alkaline } \\
\text { phosphatase }\end{array}$ & Female & 12964 & Roche Cobas & $\mathrm{U} / \mathrm{L}$ \\
\hline SSHFALPM & $\begin{array}{l}\text { Alkaline } \\
\text { phosphatase }\end{array}$ & Male & 9879 & Roche Cobas & $\mathrm{U} / \mathrm{L}$ \\
\hline SSHFTGF & Triglycerides & Female & 8727 & Roche Cobas & $\mathrm{mmol} / \mathrm{L}$ \\
\hline SSHFTGM & Triglycerides & Male & 7623 & Roche Cobas & $\mathrm{mmol} / \mathrm{L}$ \\
\hline
\end{tabular}

The underlying L,M,S-for-age entries are specified in attachment 2.

The normality Q-tests are specified in attachment 3.

\section{Declarations}

Conflict of Interest: 


\section{References}

1. Flegal KM, Cole TJ. Construction of LMS parameters for the Centers for Disease Control and Prevention 2000 growth charts. National Health Statistics Reports. 2013;(63):1-4.

2. Growth Charts - Homepage [Internet]. [cited 2021 Dec 8]. Available from: https://www.cdc.gov/growthcharts/index.htm

3. Karbasy K, Lin DCC, Stoianov A, Chan MK, Bevilacqua V, Chen Y, et al. Pediatric reference value distributions and covariate-stratified reference intervals for 29 endocrine and special chemistry biomarkers on the Beckman Coulter Immunoassay Systems: A CALIPER study of healthy community children. Clinical Chemistry and Laboratory Medicine. 2016;54(4).

4. Motulsky HJ, Brown RE. Detecting outliers when fitting data with nonlinear regression - a new method based on robust nonlinear regression and the false discovery rate. BMC bioinformatics [Internet]. 2006 Jan [cited 2014 Jul 17];7(1):123. Available from: http://www.biomedcentral.com/1471-2105/7/123

5. Rigby RA, Stasinopoulos DM, Lane PW. Generalized additive models for location, scale and shape. Journal of the Royal Statistical Society Series C: Applied Statistics. 2005;54(3):507-54.

6. Pan $\mathrm{H}$, Cole TJ. A comparison of goodness of fit tests for age-related reference ranges. Statistics in Medicine. 2004;23(11):1749-65.

\section{Supplementary Files}

This is a list of supplementary files associated with this preprint. Click to download.

- Attachment1LMSreferencecurves.zip

- Attachment2LMSentriesjson.zip

- Attachment3LMSQtest.zip 